\title{
Influence of Additional Annealing on Properties of Ni-Mn-In-Co Heusler Alloy.
}

\author{
Alexander Kamantsev ${ }^{1}$, Elvina Dilmieva ${ }^{1}$, Alexey Mashirov ${ }^{1}$, Victor Koledov $^{1}$, Vladimir Shavrov ${ }^{1}$, \\ Vladimir Khovaylo ${ }^{2}$, Maria Lyange ${ }^{2}$, Sergey Konoplyuk ${ }^{3}$, Vladimir Kokorin ${ }^{3}$, Rostislav Grechishkin ${ }^{4}$, \\ Pnina Ari-Gur 5 . \\ 1. Kotelnikov Institute of Radio-engineering and Electronics of RAS, Moscow, Russia. \\ 2. National University of Science and Technology "MISIS", Moscow, Russia. \\ 3. Institute of Magnetism of NASU and MESU, Kyiv, Ukraine. \\ 4. Tver State University, Tver, Russia. \\ 5. Western Michigan University, Kalamazoo, MI, USA.
}

A promising class of solid materials for magnetic cooling at room temperatures is that in which a first order metamagnetostructural phase transition (PT) is induced by the magnetic field [1]. In this case, socalled inverse magnetocaloric effect (MCE) originates from a structural PT from the paramagnetic or antiferromagnetic martensite phase to the ferromagnetic austenite phase on the application of a magnetic field. Recently, much interest is attracted to Ni-Mn-In-Co alloys due to large magnetic-field-induced strains [2] and giant inverse MCE [3,4]. We created the new series of Ni-Mn-In-Co alloys with 43 at. \% of $\mathrm{Ni}$ and 7 at. \% of $\mathrm{Co}$. The samples from this series were prepared by arc melting under an argon atmosphere with subsequent homogenizing annealing during 48 hours at $900{ }^{\circ} \mathrm{C}$. Metamagnetic alloy $\mathrm{Ni}_{43} \mathrm{Mn}_{37.8} \mathrm{In}_{12.2} \mathrm{Co}_{7}$ was chosen for further research. We investigated the properties of this alloy by electrical resistance measurements (ERM), differential scanning calorimetry (DSC) and energydispersive X-ray spectroscopy (EDX). After that, samples of this alloy were exposed to additional annealing during 50 hours at $750{ }^{\circ} \mathrm{C}$ and all measuring procedures were repeated.

It was determined, that electrical resistance of annealed samples is less on $30 \%$ than before annealing in martensite and austenite state too (see Fig. 1). In addition we observe a narrowing of hysteresis curve almost on $40 \%$ (from $\Delta \mathrm{T}_{\text {hyst }}=40^{\circ}$ downto $25^{\circ}$ ) and a shift of curve on $15^{\circ}$ to higher temperatures.

The martensitic transformation temperatures and the latent heat during the PT were determined by DSC at heating and cooling rates of $10 \mathrm{~K} / \mathrm{min}$. As seen from Fig. 1, DSC scans of the sample demonstrate exothermic and endothermic peaks which are associated with the martensitic PT occurring in the sample. The characteristic transition temperatures $M_{s}, M_{f}$ and $A_{s}, A_{f}$ corresponding to start and finish temperature of direct and reverse martensitic transformation, respectively, before and after additional annealing. The transition temperatures were determined as a crossing point between the extrapolation lines of the peaks and the base line. For our alloy transformation's temperatures before annealing were found: martensite start $\mathrm{M}_{\mathrm{s}}=6{ }^{0} \mathrm{C}$, martensite finish $\mathrm{M}_{\mathrm{f}}=-10{ }^{0} \mathrm{C}$ and austenite start $\mathrm{A}_{\mathrm{s}}=32{ }^{0} \mathrm{C}$, austenite finish $\mathrm{A}_{\mathrm{f}}=45{ }^{0} \mathrm{C}$. Transformation's temperatures after annealing: $\mathrm{M}_{\mathrm{s}}{ }^{\mathrm{A}}=26{ }^{0} \mathrm{C}, \mathrm{M}_{\mathrm{f}}^{\mathrm{A}}=14{ }^{0} \mathrm{C}$ and $\mathrm{A}_{\mathrm{s}}{ }^{\mathrm{A}}=$ $39{ }^{0} \mathrm{C}, \mathrm{A}_{\mathrm{f}}^{\mathrm{A}}=54{ }^{0} \mathrm{C}$. The Curie temperature of austenite state does not depend on heat treatment: $\mathrm{T}_{\mathrm{C}}=$ $150{ }^{0} \mathrm{C}$. Calculated from the DSC data the latent heat upon direct (cooling) and reverse (heating) PT are $\mathrm{L}_{\mathrm{C}}=+3.8 \mathrm{~J} / \mathrm{g}$ and $\mathrm{L}_{\mathrm{H}}=-4.3 \mathrm{~J} / \mathrm{g}$ in both cases (differences $\sim 10 \%$ - in limits of error).

The EDX analysis of samples before and after annealing was conducted; SEM micro-photos of investigated fields are presented on Fig. 2. The black areas are flaws. The white areas (martensite plates) have the following average composition in at. \%: $\mathrm{Ni}_{42.4} \mathrm{Mn}_{37.2} \operatorname{In}_{13.9} \mathrm{Co}_{6.5}$. The grey area (main body) has the similar composition. The significant difference in composition observed in dark-grey areas (the second phase): $\mathrm{Ni}_{37.4} \mathrm{Mn}_{40.0} \mathrm{In}_{1.0} \mathrm{Co}_{21.6}$. These areas have little $1 \%$ of In and a lot $21.6 \%$ of Co. One can see that annealing increases grain size and helps to reveal additional information about inner structure. 
[1] T. Krenke, E. Duman, M. Acet, et al., Nature Materials 4, (2005), p. 450.

[2] R. Kainuma, Y. Imano, W. Ito, et al., Nature 439, (2006), p. 957.

[3] J. Liu, T. Gottschall, K.P. Skokov, et al., Nature Materials 11, (2012), p. 620.

[4] A. Kamantsev, V. Koledov, E. Dilmieva, et al., EPJ Web of Conferences 75, (2014), p. 04008.

[5] The authors acknowledge funding from the Russian Sciences Foundation, Grant № 14-22-00279.
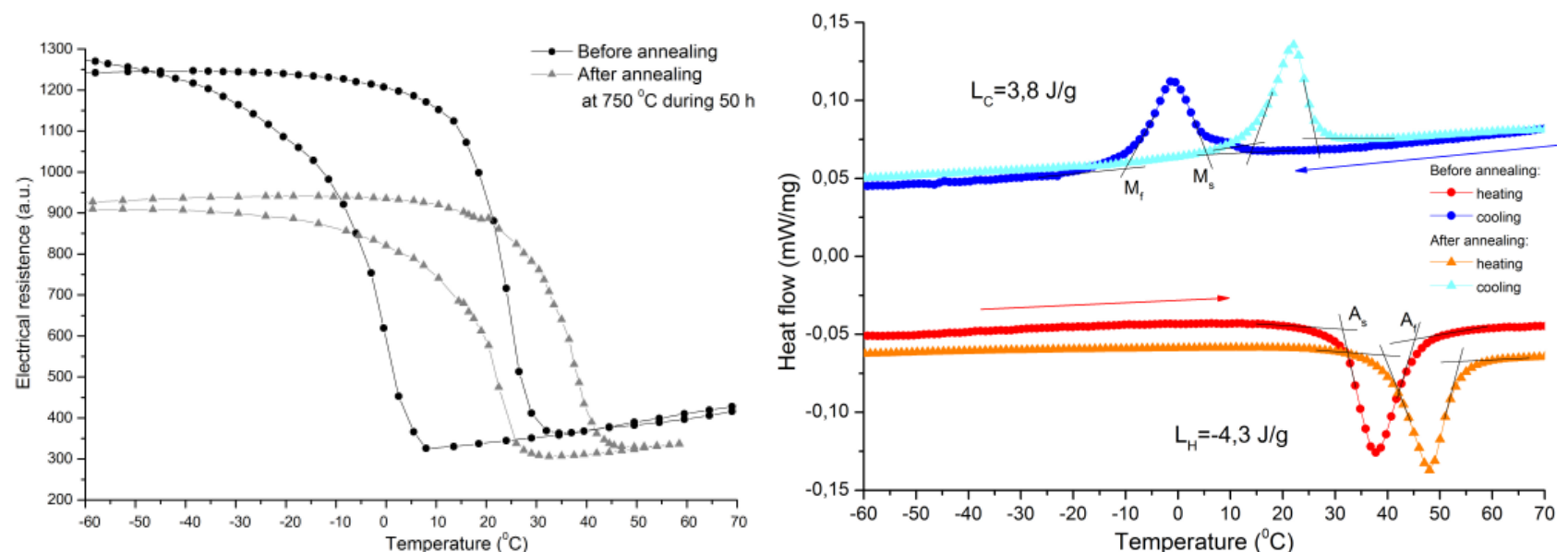

Figure 1. ERM and DSC investigations of metamagnetic $\mathrm{Ni}_{43} \mathrm{Mn}_{37.8} \mathrm{In}_{12.2} \mathrm{Co}_{7}$ alloy before and after additional annealing during 50 hours at $750{ }^{\circ} \mathrm{C}$.

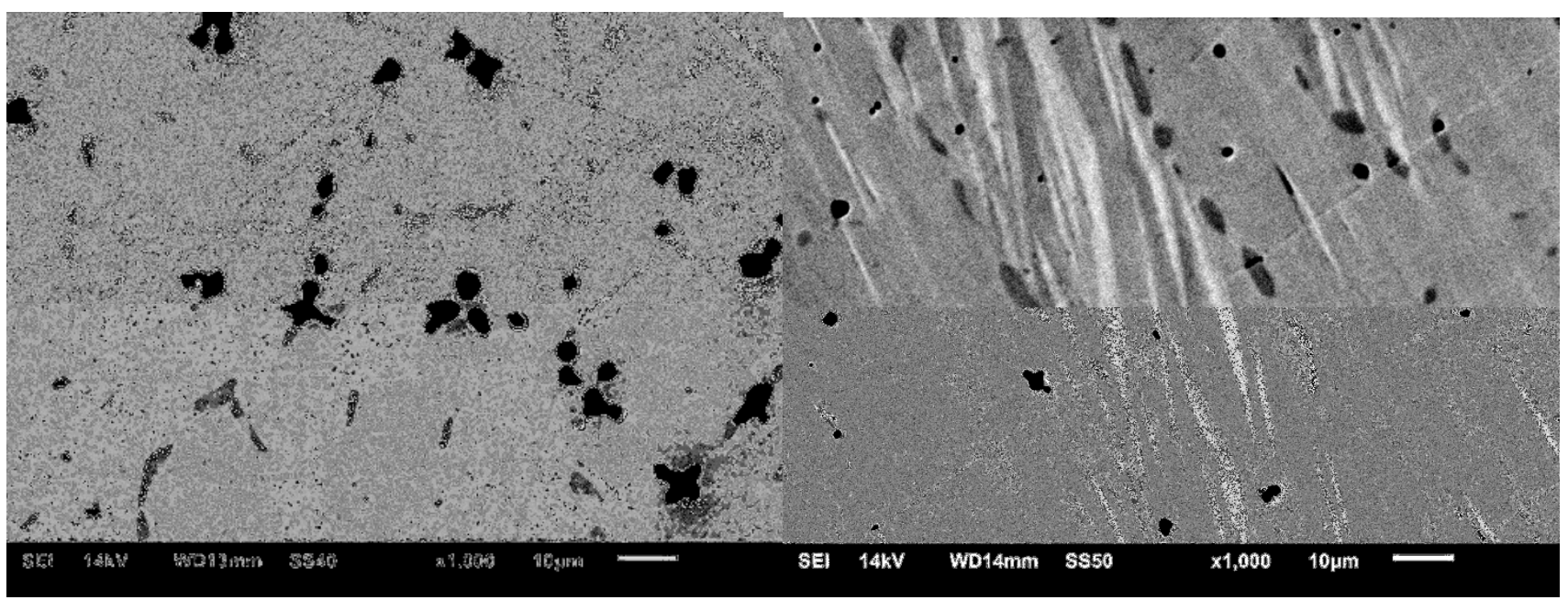

Figure 2. SEM micro-photos of region of EDX analyses of metamagnetic $\mathrm{Ni}_{43} \mathrm{Mn}_{37.8} \operatorname{In}_{12.2} \mathrm{Co}_{7}$ alloy before and after additional annealing during 50 hours at $750{ }^{\circ} \mathrm{C}$. 